\title{
Retando la norma: \\ Mujeres emancipadas
}

\section{( Dora Barrancos}

barrancosconicet@gmail.com

*UBA/IIEGE/CONICET

\section{Resumen}

El artículo revisa la noción de emancipación y su paradójica referencia en la codificación civil. El matrimonio era la vía para la autonomía de las personas menores de edad, pero en el caso de las mujeres significaba un reingreso a la subordinación. Se examinan ciertas conductas emancipadoras adoptadas por un pequeño número de mujeres en la sociedad argentina de fines del siglo XIX y XX, en diferentes escenarios sociales. Tales conductas pudieron no corresponder al plano de una completa autonomía, pero no hay dudas de que la experiencia de la conducta díscola y desafiante ha sido una marca excelsa en la vida de las congéneres.

\footnotetext{
Abstract

The article reviews the notion of "emancipation" and its paradoxical reference in civil coding. Marriage was the way for the autonomy of minors, but in the case of women meant a re-entry to subordination. We examine certain emancipatory behaviors adopted by a small number of women in Argentine society at the end of the 19th
}

Palabras clave: emancipación matrimonio mujeres 
and 2oth centuries, in different social settings. Such behaviors may not correspond to the level of complete autonomy, but there is no doubt that the experience of unruly and challenging behavior has been an excellent mark in the life of the congeners.

El concepto de emancipación presenta una doble vertiente semántica. Se trata de una noción jurídica y también de una capacidad individual que refiere a la experiencia de disponer de la voluntad de decidir, de actuar con autonomía. Esta doble perspectiva no puede perderse de vista, porque la emancipación prometida por la norma jurídica, hasta las reformas más recientes de la codificación civil, no significó efectiva libertad para las mujeres. Deseo ocuparme en este trabajo de los retos a las normas sujetadoras, de las rebeliones contra los imaginarios sojuzgadores realizados por mujeres. Pinzaré solo algunos casos desde fines del siglo XIX a mediados del XX, y seguramente resulta ocioso señalar que me escapa el enorme cúmulo de transgresoras habidas en todos los grupos sociales en la bisagra de ambos siglos. Está en foco en este análisis el desacato a reglas más que a la disposición legislativa, pues como acabo de anticipar, ampararse con la Ley que prometía la emancipación pudo significar mayor sometimiento, una clausura más ominosa de la débil independencia. Veamos el Código Civil sancionado en 1869 y puesto en ejecución en 1871, un macizo exponente del orden jurídico moderno reflejo de las mentalidades patriarcales. No pocas reglas "al uso" de las relaciones de género -relaciones basales de la sociedad- tuvieron traducción en esa normativa basada en la noción de la inferioridad femenina que había sido el sustrato del gran antecedente, el Código Civil francés de 1804-conocido como Código Napoleónico debido a la sanción bajo el régimen imperial de Napoleón Bonaparte-. Pero antes de la aparición de este, algunos antecedentes sancionaban la dominación masculina, tales los Códigos de Baviera y Prusia producidos entre 1793 y 1794. Revisitemos las reglas aseguradoras de la primacía del marido en el Código Civil argentino tal como se lee en la versión presentada por el autor del proyecto, Dalmacio Vélez Sársfield, que tuvo modificaciones al momento de su sanción:

\section{TITULO I - CAPITULO VI - Derechos y obligaciones de los cónyuges}

184. Tampoco puede la mujer, sin licencia o poder del marido, celebrar contrato alguno, o desistir de un contrato anterior; ni adquirir bienes o acciones por título oneroso o lucrativo; ni enajenar, ni obligar sus bienes; ni contraer obligación alguna, ni remitir obligación a su favor.

185. Se presume que la mujer está autorizada por el marido, si ejerce públicamente alguna profesión o industria, como directora de un colegio, maestra de escuela, actriz, etcétera., y en tales casos se entiende que está autorizada por el marido para todos los actos o contratos concernientes a su profesión o industria, si no hubiese reclamación por parte de él, anunciada al público o judicialmente intimada a quien con ella hubiese de contratar. Se presume también la autorización del marido, en las compras al contado que la mujer hiciese, y en las compras al fiado de objetos destinados al consumo ordinario de la familia.

186. Bastará que la mujer sea solamente autorizada por el juez del domicilio, cuando estuviese el marido demente o en lugar no conocido; en los casos del art. 177, por ser menor el marido o la mujer, y se hubiesen casado sin las autorizaciones necesarias; o en los casos del art. 135, en cuanto a los actos que los menores casados no pueden ejecutar.

187. Los tribunales, con conocimiento de causa, pueden suplir la falta de la autorización del marido cuando este se hallare ausente o impedido para darla, o la 
rehusare sin motivo fundado, y ella fuese necesaria y útil a la mujer o al matrimonio.

188. El marido puede revocar a su arbitrio la autorización que hubiere concedido a su mujer, pero la revocación no tendrá efecto retroactivo en perjuicio de tercero.

189. El marido puede ratificar general o especialmente los actos para los cuales no hubiese autorizado a su mujer. La ratificación puede ser tácita por hechos del marido que manifiesten inequívocamente su aquiescencia.

La redacción del Artículo 185 se acotó notablemente durante el tratamiento parlamentar y hasta cambió de numeración debido al arreglo de capítulos, de modo que los ejemplos dados por Vélez Sársfield desaparecieron en el texto aprobado, pero no deja de llamar la atención que se trataba de dos funciones muy disímiles en el valor social acordado al desempeño de las mujeres, aunque resultaba claro para el codificador que se trataba de inexorables exposiciones públicas. El magisterio femenino gozaba de todo reconocimiento y un cargo de jefatura en el medio educativo no podía tener obstáculos de autorización marital, pero si lo hubiera se indicaba que debía convalidarse públicamente. En el caso de la actividad actoral, contrastante con la axialidad corriente de la época, cualquier disenso del cónyuge también parecía exigir una manifestación pública ("anunciada al público o judicialmente"-se lee en la redacción original-). El Código Civil finalmente sancionado no hizo referencia al modo público en que el marido debía oponerse a la actividad laboral de las mujeres -aunque podía recurrir a los estrados judiciales en caso de que la cónyuge se resistiera a la decisión-.

La disminución de la capacidad de las mujeres al casarse resultó contradictoria con la norma del mismo Código que estableció las condiciones de la emancipación. En efecto, las personas se emancipaban cuando eran mayores de edad, pero los menores se emancipaban con el matrimonio, derecho que permanecía, aunque hubiera separación en el lapso de la minoridad. Por lo tanto, casarse fue para las mujeres un modo de emanciparse de patriarcas parentales y una buena cantidad de matrimonios, desde fines del siglo XIX, pudieron significar la huida de situaciones intolerables en hogares de mucho hostigamiento, y desde luego, paradójicamente, asegurarse el ingreso a más acentuadas sujeciones, cuando no a avernos inenarrables. Desearía detenerme en algunas cuestiones referidas a la emancipación.

En primer lugar, es necesario admitir que la emancipación a menudo está lejos de la integralidad, es generalmente parcial y refiere a una zona de la estructura del sujeto. La emancipación corresponde a una dimensión de la existencia y puede haber contradicciones entre las "racionalidades múltiples" (Deleuze y Guattari, 1994) en la que una fórmula del sometimiento resulte exonerada de la conducta y no obstante haya acatamiento a la "regularidad normativa" en otras manifestaciones de la subjetividad. Desistamos, por lo tanto, del concepto de "totalidad", pues supone un plano dominante y organizador de todos los aspectos del sujeto. Deberíamos determinarnos, sin embargo, sobre ciertos ángulos en los que es posible argumentar sobre la emancipación de no pocas mujeres, y seguramente es más adecuado concluir que, más que sujetos completamente autónomos, estamos frente a quienes han mostrado "conductas emancipadas", aunque un acierto de auspicio empático nos conduzca a subrayar el carácterintegral de las "mujeres emancipadas".

En segundo lugar, debe reflexionarse acerca de que el propio concepto de emancipación -tan caro a la tradición feminista- puede encontrar problemas cuando se examinan ciertos feminismos esencialmente diferencistas. Estos suelen sospechar que los objetivos de los feminismos de la igualdad -en orden a conseguir la "idéntica condición de los varones"- finalmente arrollan el sentido de la emancipación y la hacen equivalente al estatuto que gozan los varones. Rossi Bradidotti examinó 
la diatriba que enfrentan por un lado a las "antiemancipatorias" (Rossi Bradidotti, 2000) y esencialistas -forjadas en un diferencismo a ultranza- y por otro a las "igualitarias/identitarias" (Rossi Bradidotti, 2000), que sostienen posiciones que, a su juicio, resultan también falaces cuando aseguran una construcción emancipadora integral.

Finalmente, podríamos conjeturar que el concepto emancipación solo puede aplicarse de manera situada, esto es dentro de las condiciones de posibilidad de los constructos femeninos -y también masculinos y de otredades de género-, en contextos de significación que no pueden ser absolutos. Con esto quiero expresar que no se puede absolutizar un término situacional, porque siempre debe pensarse en los puntos de vista, en los anclajes existenciales que producen ideas y valores que de cualquier modo impiden la operación de tomar como absolutos ciertos principios, por ejemplo, el de libertad. Es cierto que no hay negociación posible en lo que refiere a derechos humanos y que es necesario abdicar de cualquier supuesto de relativismo cultural ya que el propio relativismo es tan amenazante como el universalismo, puesto que fosiliza los elementos vernáculos de una cultura, y los torna inamovibles y ahistóricos. El camino de la emancipación de las mujeres solo puede garantizarse en una perspectiva de "creación de un modelo democrático deliberativo que permita la máxima controversia cultural dentro de la esfera pública" (Benhabib, 2006: 9).

Presentaré a continuación tres casos de mujeres en cuyas vidas se manifestaron destellos de emancipación. He examinado a las dos primeras en anteriores abordajes e insistiré en algunas caracterizaciones y conclusiones, pero con relación a la tercera protagonista, que ha sido objeto de diversas investigaciones, es mi primera incursión y debo adelantar que me detendré especialmente en ella, porque tal vez exhiba un despliegue más incisivo, más amplio y más temerario del empeño emancipador que anida en toda subjetividad femenina.

\section{Revisitando a mujeres con conductas emancipadas}

Entre las mujeres que quebraron los lazos de sumisión a fines del siglo XIX se encuentra Amalia Pelliza Pueyrredón, de quien me he ocupado en otro lugar. Casada cuando era una adolescente -era moneda corriente el casamiento de las jóvenes antes de los veinte años-, su marido fue el médico Carlos Durand, figura muy proyectada ya que fue diputado y luego senador por Buenos Aires. Pero tal vez la mayor consideración social devino del ejercicio de la obstetricia, ya que a su consultorio concurrían las mujeres de la elite porteña. Todo indica que Amalia fue obligada a ese casamiento por razones estratégicas, pues la familia pasaba por muchas dificultades. Tenía varias hermanas, entre las cuales Josefina, que se destacó en las letras, murió joven y poco se sabe de su relación con Amalia. En algún momento Amalia fue forzada a mantenerse en el interior del hogar con escasas posibilidades de efectuar paseos o visitas. Durand había evolucionado hacia un carácter cada vez más iracundo, al parecer esto se evidenció después de que Amalia fuera acometida por una viruela que dejó severas marcas en su rostro. La situación de encierro era también tutelada por Carolina Durand, hermana del facultativo que, finalmente, frente a los reclamos de Amalia, decidió escarmentarla comprando un carruaje de características deplorables, comparado con los que empleaban los sectores de alcurnia. Nuestra mujer exhibió una conducta reivindicativa cuando inició un juicio de divorcio en el que seguramente alegó que su vida estaba en peligro, pero el resultado fue adverso. Durand enfermó gravemente y fue la ocasión para que Amalia disfrutara de mayor libertad, pero cuando se restableció recrudecieron las medidas de control. Fue entonces que huyó de la casa, un acto temerario dadas todas las circunstancias de su existencia. Al morir Durand dejó un testamento en el que la desheredaba por completo, aunque el Código Civil 
establecía el derecho a la mitad de los bienes gananciales. La fortuna del médico era enorme, pues, entre otros, poseía numerosos bienes raíces. Había determinado que una parte importante de la fortuna fuera destinada a la creación de un hospital de hombres y repartió algunas cuantías menores para un grupo de mujeres, su hermana y algunas criadas, y esta selección de herederas no deja de significar una suerte de escarnio para Amalia. Esta se presentó a reclamar lo que le pertenecía y, finalmente, con certeza asesorada por sus abogados, decidió aceptar una parte magra de lo que le pertenecía. Se sabe que gastó ese recurso en viajes a Europa y que murió de manera humilde. Amalia, vista en perspectiva no anacrónica, pudo emanciparse de un marido que se comportaba con la plena autorización del orden jurídico, orden que aseguraba sus prerrogativas al punto que la justicia le denegó la separación. Resulta difícil imaginarla emancipada en todos los planos, muy probablemente no se ganó la vida en alguna actividad y no sabemos si se encaminó a discutir públicamente los derechos de las mujeres a inicios del siglo XX cuando transcurrió su vida libre. Pero no puede dejar de reconocerse que su paso liberador constituyó un muñón en la perspectiva de las conductas emancipadoras femeninas.

Otra mujer de características singulares en la investigación historiográfica que he realizado, es Amelia Carreras, la telefónica que se animó a un acto arrojado, tal vez inesperado para las características que pueden conjeturarse de su personalidad. Amelia había nacido en Cuba y es muy probable que su familia se trasladara al país luego de la guerra anticolonial en aquel territorio. Eran varias hermanas y al menos dos ingresaron a la compañía inglesa de telefonía, la Unión Telefónica. El servicio de telefonía adquirió rápidamente normas taylorianas en la mayor parte de sus actividades, en especial en las destinadas a la atención directa de las comunicaciones, para lo cual se contrataban muchachas muy jóvenes. Pero lo más idiosincrático de la industria telefónica en el mundo, era que en el sector comercial gravitante, que hacía posible la comunicación, se impedía el ingreso de las mujeres casadas. Las telefonistas-pensaban las gerencias empresariales-debían permanecer solteras, porque esto garantizaba el completo acatamiento a las normas y era menester una disciplina rígida que respondiera a las necesidades del servicio. El exigente régimen laboral implicaba que mientras las muchachas estaban en el conmutador no se podían expresar de ninguna otra manera que lo prescripto por el manual del "método". Jamás podían manifestar alguna frase que alterara la prevista neutralidad mecánica indicada por la norma. La tarea solía ser extenuante y además, hasta los cambios tecnológicos de mediados del siglo XX, la atención con los auriculares tenía el conocido riesgo del golpe de magneto, que en numerosos casos limitó la audición de las trabajadoras.

Amelia no adhirió a la huelga de marzo de 1919 -se trató de uno de los primeros movimientos reivindicativos en la telefonía-, circunstancia que llevó a la Unión Telefónica a determinar que una parte de los planteles que se desempeñaba en las secciones céntricas de la empresa pernoctara en los propios lugares de trabajo para garantizar la atención del servicio. Es muy probable que Amelia fuera de las que se quedaron a dormir en su puesto de trabajo. No solo no acató la huelga, sino que he encontrado evidencias de que facilitó el control que se ejerció sobre los huelguistas. En 1921, cuando ya había cumplido casi quince años de desempeño en la empresa -no le habían faltado incidentes con algunas compañeras- y había accedido a un cargo más alto, asimilado al de supervisora, de manera subrepticia contrajo enlace y fue denunciada mediante una pequeña nota anónima que firmaban "varios abonados". Resulta evidente que se había demorado mucho en esa decisión, pues tenía treinta y un años al momento de matrimoniarse, una edad "excesiva" para los códigos de la época. Entonces tronó el escarmiento y la empresa decidió cesantearla. Fueron días con certeza angustiantes para Amelia quien clamó por la reincorporación, que le fue denegada y otro tanto ocurrió con las tentativas de obtener un puesto de telefonista en la empresa de tranvías -que también pertenecía al mismo grupo inglés-. La 
desesperación hizo lo suyo y se decidió esperar al Director General de la compañía, J.E.Parker, en la vereda de su casa en la calle Libertad al 1000 de Buenos Aires. Le pidió que le devolvieran el trabajo y frente a la negativa le clavó un cuchillo en la espalda. Fue una herida de poca monta, pero es imaginable la alharaca desatada por la actuación de nuestra mujer. El juez que trató la causa encontró -con rotunda lógica patriarcal- que era contradictorio que se impidiera el matrimonio a una mujer cuando esa era el destino esperado para la condición femenina. Siendo primaria en materia de delitos y considerando que se había tratado de una tentativa, el fallo la condenó a ocho meses de prisión domiciliaria, y fue escandaloso para la compañía.

No sabemos cuál fue el destino de Amelia Carreras, pero su conducta, cercana a lo trágico, fue una llamarada insurrecta. Insisto sobre la perspectiva del análisis que efectué cuando investigué su caso: Amelia no había manifestado identidad de clase y hasta donde se sabe no se incorporó a las luchas por los derechos femeninos, pero ¿cómo no asignarle una reivindicación que enlaza de modo inescindible los términos, aunque su conducta hubiera sido más desatinada que consciente? Involuntariamente, pero es lo de menos, su acto exasperado mostró una Amelia resuelta a enfrentar la ignominia del despojo y fue un signo soberbio de emancipación.

Finalmente me demoraré en una mujer singular, Josefa América Scarfó. Fina o América, como solía llamársela, siendo adolescente se enamoró de quien se transformaría en una de las figuras trágicas del anarquismo argentino, Severino Di Giovanni. Vayamos a la época y sus protagonistas. Durante la década de 1920 el anarquismo presentó un quiebre profundo que se expresó en la existencia de dos grandes formaciones internas que respondían a una interpretación ciertamente diferenciada de la realidad. Por un lado, se manifestaron los grupos identificados con el ideario y metodología de acción de La Protesta, que había sido el órgano rector de las fuerzas libertarias. En la vereda de enfrente se ubicaron núcleos cuya identificación generalizada se estableció en torno de LaAntorcha, con proyección mayor en las áreas del interior del país, en donde fue arraigando una mayor radicalidad del espectro libertario. He ahí una de las razones del enfrentamiento entre las dos orientaciones: el grupo antorchista reclamaba volver a las formas más severas de enfrentamiento con el sistema conformado por el Estado, el patronato y la Iglesia, y aunque difícilmente prohijara por completo las acciones violentas, entre sus adherentes se desarrollaron sentimientos y prácticas que las legitimaban. El anarquismo protestista lucía más adaptado y en su seno se condenaban sin tapujos los métodos iracundos. Es necesario evocar que en las concepciones libertarias las exacciones y las ejecuciones a los enemigos de los obreros debían caracterizarse como actos de justicia. En nuestro país el último gran atentado había ocurrido en noviembre de 1909, cuando Simón Radowitzky -un muy joven obrero llegado de Ucrania- ultimó al coronel Ramón Falcón, el célebre jefe de policía a cuyo cargo estuvieron represiones violentas, como el desalojo de las familias participantes de la huelga de inquilinos de 1907, y era especialmente sindicado como el responsable de la matanza de alrededor de once participantes de la manifestación del $1^{\circ}$ de Mayo de 1909. La corriente que sostenía que era necesario sacudir el adormecimiento y recurrir a las formas violentas como método decisivo para terminar con el dominio del estado y la burguesía, tuvo en Severino Di Giovanni un intérprete singular, aunque en verdad su adscripción anarquista respondía a un encuadramiento individualista. Había llegado de Italia en 1923 con su esposa Teresa -de la que era primo- y una niña, huyendo del fascismo. Se había desempeñado como maestro, aunque todo indica que no había podido graduarse, y que luego trabajó como tipógrafo -tarea especialmente apta para quienes tenían buen dominio de la lectoescritura-. Se instaló con la familia en la región oeste, cercana a la capital, y se vinculó rápidamente al anarquismo local a través de grupos antorchistas, pero decidió hacer un camino radicalizado propio. A mediados de la década 1920 inició la publicación Culmine y lideró un grupo que optó por la acción "por los hechos", que cometieron 
diversos robos y asaltos, acciones que tenían el doble significado de la apropiación y de la vindicta de los despojados. Di Giovanni poseía una personalidad acendrada en la voluntad de acción y su vocación justiciera lo determinó en el sentido de que lo único posible era la expropiación y hacer justicia según los códigos éticos libertarios. Osvaldo Bayer en el libro que le dedicó relata:

Singular naturaleza la de este hombre. Se movía permanentemente en una emocionalidad entre lo heroico y lo romántico que se desbordaba con generosidad por sobre los límites de lo ordinario, lo común, lo legal, el orden constituido. Jamás podría haber entendido lo que son impuestos, multas, reglamentaciones, ordenanzas, patentes, leyes, propiedad. La sociedad afincada en esos principios se iba a defender con uñas y dientes de este peligroso dogmático del libre albedrío. (Bayer, 1998: 196)

Severino y su familia fueron a vivir en 1925 a una casa alquilada a los padres de dos compañeros anarquistas, Paulino y Alejandro Scarfó, quienes vivían en un inmueble lindante, y debe señalarse que Paulino fue uno de los más decididos integrantes del núcleo liderado por Severino. Los hermanos tenían un padre de talante autoritario y una hermana adolescente, América, quien fue atraída por el joven Severino, ese muchachón de porte decidido y de bella estampa. La atracción fue creciendo entre ambos y el amor finalmente los enlazó de modo inquebrantable. Severino, que sorteaba la persecución policial, debió refugiarse en el Tigre y se tornó muy difícil la vinculación asidua con América. Ella concurría al liceo Estanislao Zevallos $\mathrm{N}^{\circ} 2$ en el centro de Buenos Aires, era buena alumna y Severino solía procurarla. La treta era aguardarla a la salida del subte, iniciar una caminata y aguardar que se le acercara América sin que lo advirtieran sus compañeras. El cerco se fue cerrando sobre Severino y su grupo de "expropiadores", de modo que hubo que encontrar un nuevo refugio, y frente a la situación de alejamiento de la amada América -a la sazón vigilada por sus padres que se oponían a la relación-, ambos tomaron la decisión de fraguar un casamiento con el joven militante Silvio Astolfi. ${ }^{1}$ Esta circunstancia temeraria significó la emancipación legal de la muchacha, el modo de abandonar su casa junto a Silvio quien de inmediato la llevó a convivir con Severino en Burzaco, en una quinta a la que pusieron "Ana María", adoptaron seudónimos y se granjearon de la simpatía de los vecinos. Ella se había revelado como una adherente a la causa libertaria, algo que se traduce de modo claro en la carta que envió, en diciembre de 1928, a Émile Armand -seudónimo de Ernest-Lucien Juin, un referente del anarquismo individualista francés, caracterizado propagandista de la libertad sexual, entre otras cuestiones-:

Querido camarada: El motivo de la presente es, principalmente, consultarlo. Tenemos que actuar, en todos los momentos de la vida, de acuerdo a nuestro modo de ver y de pensar, de manera que los reproches o las críticas de otra gente encuentren a nuestra individualidad protegida por los más sanos conceptos de responsabilidad y libertad en una muralla sólida que haga fracasar a esos ataques. Por eso debemos ser consecuentes con nuestras ideas. Mi caso, camarada, pertenece al orden amoroso. Soy una joven estudiante que cree en la vida nueva. Creo que, gracias a nuestra libre acción, individual o colectiva, podremos llegar a un futuro de amor, de fraternidad y de igualdad. Deseo para todos lo que deseo para mí: la libertad de actuar, de amar, de pensar. Es decir, deseo la anarquía para toda la humanidad. Creo que para alcanzarla debemos hacer la revolución social. Pero también soy de la opinión de que para llegar a esa revolución es necesario liberarse de toda clase de prejuicios, convencionalismos, falsedades morales y códigos absurdos.

Severino hacía tiempo que se había separado de Teresa, pero no abandonó su sostén y el de sus hijos -la pareja había tenido una niña y un niño más-, que llegaron a
Silvio Astolfi era un joven anarquista de origen italiano. Se alistó en la Guerra Civil española y murió en ella. 
2 Salvadora Medina Onrubia fue una conocida escritora anarquista. Se casó con el controvertido Natalio Botana luego dueño del diario Crítica firas iconoclastas. A ella se debe la liberación de Simon Radowitzy del penal de Tierra del Fuego.

3 No ha sido posible identificar las publicaciones de América Scarfó. tener un buen vínculo con América. Severino fue sorprendido cuando concurrió a la imprenta, que de modo clandestino realizaba trabajos para su grupo en Buenos Aires. Pudo escapar, pero fue aprehendido tras una balacera que también mató de modo involuntario a una niña. Fue llevado herido al penal que entonces se erguía sobre la calle Las Heras y acusado de una serie de actos criminales, entre los más graves estaban la voladura del City Bank, que rindió dos muertos en diciembre de 1927, y el atentado al consulado de Italia en mayo de 1928, en el que murieron nueve personas. También se lo hizo responsable del asesinato de Emilio López Arango -acaecido en 1928-, el director de La Protesta, que representaba la jefatura anarquista de los que se oponían a los métodos de Di Giovanni. El periódico le dedicaba durísimas diatribas, sostenía que eran incompatibles con el anarquismo el bandidaje y la violencia.

A poco de ser detenido Severino y otro activista, la policía cercó la quinta "Ana María", hubo un tiroteo en la que murieron dos integrantes del grupo anarquista y Paulino resultó apresado y conducido también a la cárcel de la calle Las Heras. El juicio a que fueron sometidos fue absolutamente expeditivo, memorable por lo acelerado del trámite y brutal por el fallo que determinó la pena de muerte para ambos. América lo sostuvo con singular desvelo, estuvo cerca de su amado todo lo que le fue permitido. Hay fotografías en diversos medios gráficos de la época que la muestran visitando el penal, acompañada por la hija mayor de Severino. No hay dudas del amor entrañable que la ligaba al idealista que reivindicaba la violencia y que fue fusilado el $1^{\circ} \mathrm{de}$ febrero de 1931. América también despidió a su querido hermano Paulino, fusilado al día siguiente.

Nuestra mujer pudo sobreponerse al dolor de esas pérdidas. Se le incautaron pertenencias valiosas, entre las cuales estaba la correspondencia que había sostenido con su amado cuando ocurrió el asalto a su casa de Burzaco. Con el correr del tiempo pareció crecer una suerte de mandato cifrado en la expectativa de la libertad de juicio y de conducta, "¡América lee!"-tal fue el improbable sermón patriarcal de Severino-. La lectura como medio anular para desarrollar la libertad del espíritu era parte del legado iluminista absorbido por el exacerbado romántico que terminó trágicamente. Pasaron los años en los que pudo trabajar en el diario Crítica-tal vez gracias a los oficios de Salvadora Onrubia, ${ }^{2}$ aunque no ha sido constatado- y en el inicio de la década 1940, ya con una nueva pareja, llevaron adelante el proyecto editorial AMÉRICA $L E E$, que alcanzó singular proyección. América tuvo un desempeño fundamental en esa empresa, pero siguió el imperativo de aumentar su formación. Por algún tiempo había escrito para revistas anarquistas del exterior, abordando, entre otros temas, sobre la condición de las mujeres. ${ }^{3}$ Con casi ochenta años se recibió de traductora pública del idioma francés y emprendía el traductorado de italiano. En julio de 1999 el Estado le devolvió el manojo de las cuarenta y ocho cartas que habían intercambiado con Severino, y en el menguado acto ceremonial, llevado a cabo en la Casa de Gobierno, no se privó de señalar que desde ese lugar había salido la orden de fusilamiento de sus seres queridos y también las resoluciones de acerca de muertos y desaparecidos durante la dictadura militar. Murió en agosto de 2006 con noventa y tres años.

América representa en esta galería la figura femenina más disruptiva, un reservorio de las posibilidades refractarias al adocenamiento. El ímpetu emancipador fue inexorable y no parece haber tenido solución de continuidad a lo largo de su vida. Todas las facetas de su existencia exhiben reverberos insolentes y hasta donde sabemos no abdicó de las manifestaciones iconoclastas. Probablemente su conducta corrija el presupuesto con que inicié este trabajo, la idea de una cierta imposibilidad de integralidad en la gesta emancipadora. Tal vez América siga siendo la gran retadora de esa perspectiva: amó contrariando las normas, fraguó un matrimonio como atajo para emanciparse, se sostuvo trabajando, fue ariete fundamental de una empresa cultural, se empeñó en 
estudiar hasta el fin de sus días y siguió enfrentando al Estado por la insensatez de su orden. Vida femenina que destella insurrección y dignidad. Se impone celebrarla. 


\section{Q Bibliografía}

"Barrancos D. (2000). “Inferioridad jurídica y encierro doméstico”. En F. Gil Lozano. V. Pita y G. Ini (Directoras), Historia de las mujeres en la Argentina Tomo I. Buenos Aires, Argentina: Taurus.

"Barrancos D. (2008) “La puñalada de Amelia (o cómo se extinguió la discriminación de las mujeres casadas del servicio telefónico en la Argentina)". Trabajos y Comunicaciones, $N^{\circ} 34$.

» Bayer O. (1998). Severino Di Giovanni, el idealista de la violencia. Buenos Aires, Argentina: Planeta.

»Benhabib S. (2006) Las reivindicaciones de la cultura. Igualdad y diversidad en la era global. Buenos Aires, Argentina: Katz.

»Braidotti R. (2000) Sujetos nómades. Madrid, España: Paidos.

»Deleuze G., Guattari F. (1994), Mil mesetas. Capitalismo y esquizofrenia. Valencia, España: Pre-Textos.

»Digesto Civil y Comercial. Normas de interés al fuero civil\&comercial de la Provincia de Buenos Aires [Sitio web] <https://digestocivilcomercial.wordpress.com/ digesto-procesal-civil-y-comercial/codigo-civil-de-velez-con-notas> [Consulta junio de 2016]

» Fernández Cordero L. (2017). Amor y anarquismo. Experiencias pioneras que pensaron y ejercieron la libertad sexual. Buenos Aires, Argentina: Siglo veintiuno.

» Magagnoli M. L. (1997). Un café muy dulce. Buenos Aires, Argentina: Aguilar.

»Periódico El Sol Ácrata. América Scarfó: carta a Emile Armand [sitio web]. Desierto de Atacama, Chile, 4 de mayo de 2012. <https://periodicoelsolacrata. wordpress.com/2012/05/04/america-scarfo-carta-a-emile-armand/>. 